\title{
Effect of Pilates Exercises on Standing, Walking, and Balance in Children With Diplegic Cerebral Palsy
}

\author{
Hanaa Mohsen Abd-Elfattah, $\mathrm{PhD}^{1}$, Dina Othman Shokri Morsi Galal, $\mathrm{PhD}^{2}$, \\ Mahmoud Ibrahim Elsayed Aly, $\mathrm{PhD}^{3}$, Sobhy M. Aly, $\mathrm{PhD}^{4,5}$, Tamer Emam Elnegamy, $\mathbf{P h D}^{6}$
}

\begin{abstract}
${ }^{1}$ Department of Physical Therapy for Pediatrics and Pediatric Surgery, Faculty of Physical Therapy, Badr University in Cairo, Cairo; ${ }^{2}$ Department of Physical Therapy for Orthopedic Disorders and its Surgery, Faculty of Physical Therapy, Badr University in Cairo, Cairo; ${ }^{3}$ Department of Basic Science, Faculty of Physical Therapy, Badr University in Cairo, Cairo;

${ }^{4}$ Department of Biomechanics, Faculty of Physical Therapy, Cairo University, Cairo, Egypt;

${ }^{5}$ Department of Medical Rehabilitation Sciences, College of Applied Medical Sciences, Najran University, Najran;

${ }^{6}$ Departments of Physical Therapy and Health Rehabilitation, College of Applied Medical Sciences, Princes Sultan bin Abdulaziz University, Alkharj, Kingdom of Saudi Arabia
\end{abstract}

Objective To analyze how Pilates exercises affect standing, walking, and balance in children with diplegic cerebral palsy throughout a 10-week program.

Methods We included 40 children aged 7-9 years with diplegic cerebral palsy, and randomly allocated them into two groups of the same size: conventional therapy group (group A) and conventional therapy+Pilates group (group B). We administered the same conventional physical therapy program to both groups for 45 minutes, with group B receiving additional Pilates exercises for 45 minutes. Both groups attended the intervention program three times/week for 10 weeks. We used the Growth Motor Function Measure Scale (GMFM-88) to evaluate standing and walking (Dimensions D and E), and the Pediatric Balance Scale to evaluate balance function before and after treatment.

Results Comparison of the average values of all measured variables before and after therapy showed a statistically significant difference $(\mathrm{p}<0.05)$ between the two groups. All measured variables showed a significant difference between groups $A$ and $B$, in favor of group $B(p<0.05)$.

Conclusion Pilates exercise in addition to conventional therapy is more effective in improving balance and gross motor function in children with diplegic cerebral palsy than the conventional therapy alone.

Keywords Cerebral palsy, Spastic, Diplegic, Therapy, Rehabilitation

Received September 1, 2021; Revised October 6, 2021; Accepted November 15, 2021; Published online February 28, 2022

Corresponding author: Hanaa Mohsen Abd-Elfattah

Department of Physical Therapy for Pediatrics and Pediatric Surgery, Faculty of Physical Therapy, Badr University in Cairo, Cairo 11571, Egypt. Tel: +201009106127, Fax: +0228650400, E-mail: Hanaa753@gmail.com

ORCID: Hanaa Mohsen Abd-Elfattah (https://orcid.org/0000-0003-0018-8878); Dina Othman Shokri Morsi Galal (https://orcid.org/0000-0001-59631569); Mahmoud Ibrahim Elsayed Aly (https://orcid.org/0000-0003-1634-8741); Sobhy M. Aly (https://orcid.org/0000-0003-1666-2802); Tamer Emam Elnegmy (https://orcid.org/0000-0002-5011-8619).

(c) This is an open-access article distributed under the terms of the Creative Commons Attribution Non-Commercial License (http://creativecommons.org/ licenses/by-nc/4.0) which permits unrestricted noncommercial use, distribution, and reproduction in any medium, provided the original work is properly cited. Copyright () 2022 by Korean Academy of Rehabilitation Medicine 


\section{INTRODUCTION}

Cerebral palsy (CP) is a group of persistent, nonprogressive neurodevelopmental disorders induced by immature brain injury or dysfunction that can occur throughout life. CP influences posture, voluntary movement, and the capacity to perform organized and meaningful movements. A broad range of disorders affects communication abilities, motor skills, cognitive ability, perception, sensation, and psychosocial behavior [1].

Spasticity, muscle contraction, bony malformations, loss of selective motor control, and muscle weakness are potential factors that interfere with normal gait patterns in CP. Recent studies have found that muscle weakness limits motor function in children with CP more than spasticity. Therefore, strengthening weak muscles is essential for spasticity management to improve the function of spastic diplegic CP [2].

Balance disorder is a serious problem for children with spastic diplegic $\mathrm{CP}$, and this can make it difficult to achieve and maintain equilibrium. Children with spastic diplegic CP have reduced neuromotor perceptual function, inadequate stance stability in different sensory settings, slow anticipatory response, and inaccurate preparatory activation. Although conventional treatment methods in this population have been studied, exercises such as Pilates procedures are yet to be studied in this population [3,4].

Contrology is a term for Pilates activities that focus on the concept of muscle control. It emphasizes the development of a neutral spine to avoid excessive flexion and extension while walking upright $[5,6]$.

Pilates consists of stretching, strengthening, and coordinating exercises $[7,8]$. It depends on six fundamental concepts: breathing, control, centering, flexibility, concentration, and accuracy [9]. Researchers have examined the impact of Pilates in healthy adults $[7,10]$, the elderly [5,11], and people with musculoskeletal disorders $[8,12,13]$. Pilates increases the flexibility of the trunk $[4,14]$, the strength and endurance of the abdominal, and trunk muscles $[10,14]$, and the activation of deep core muscles $[8,15]$.

Therefore, it can be suggested that Pilates can enhance the body's ability to relax, produce muscle contraction, and increase strength, flexibility, and balance. Therefore, it might be acceptable to conclude that children with
CP who can carry out functional tasks, such as standing and walking, but still need to improve the components needed for controlled movements, such as joint flexibility, muscle strength, postural stability, and mobility, may benefit from Pilates' straining.

\section{MATERIALS AND METHODS}

\section{Study design}

A single randomized blind study was conducted at the Faculty Physical Therapy outpatient clinic, Badr University in Cairo.

\section{Randomization and allocation}

We recruited 50 children with spastic diplegic CP. We excluded eight children who did not fulfill the inclusion criteria, and two children whose parents did not give their consent. Following the baseline measurements, we randomly assigned eligible children to either group A (conventional therapy group) or group B (conventional therapy group+Pilates group). A researcher who was not engaged in sample recruitment performed the randomization procedure. He coded randomization data using Microsoft Excel software (Microsoft Corporation, Redmond, WA, USA) and concealed the allocation in sealed, non-transparent envelopes with sequential numbers. The participants were then referred to a researcher who randomly assigned them to one of the study groups. Researchers responsible for evaluations were blinded to participant allocation. The experimental design is shown in Fig. 1.

\section{Participants}

We enrolled 40 children with diplegic CP (23 boys and 17 girls) in this study. The inclusion criteria were: age 7 to 9 years and diplegic $\mathrm{CP}$ diagnosis confirmed by magnetic resonance images obtained from patient records and mild spasticity of the lower limbs according to the Modified Ashworth Scale (MAS) grade 1 to $1+[16]$. We classified the participants into levels I-II based on the Gross Motor Function Classification Scale (GMFCS) [17]. The children were cognitively qualified and capable of understanding and following instructions. Patients with fixed contracture, spinal or limb malformations, visual or respiratory disorders, rhizotomy, or injection of botulinum toxin into the lower limb muscles during the 


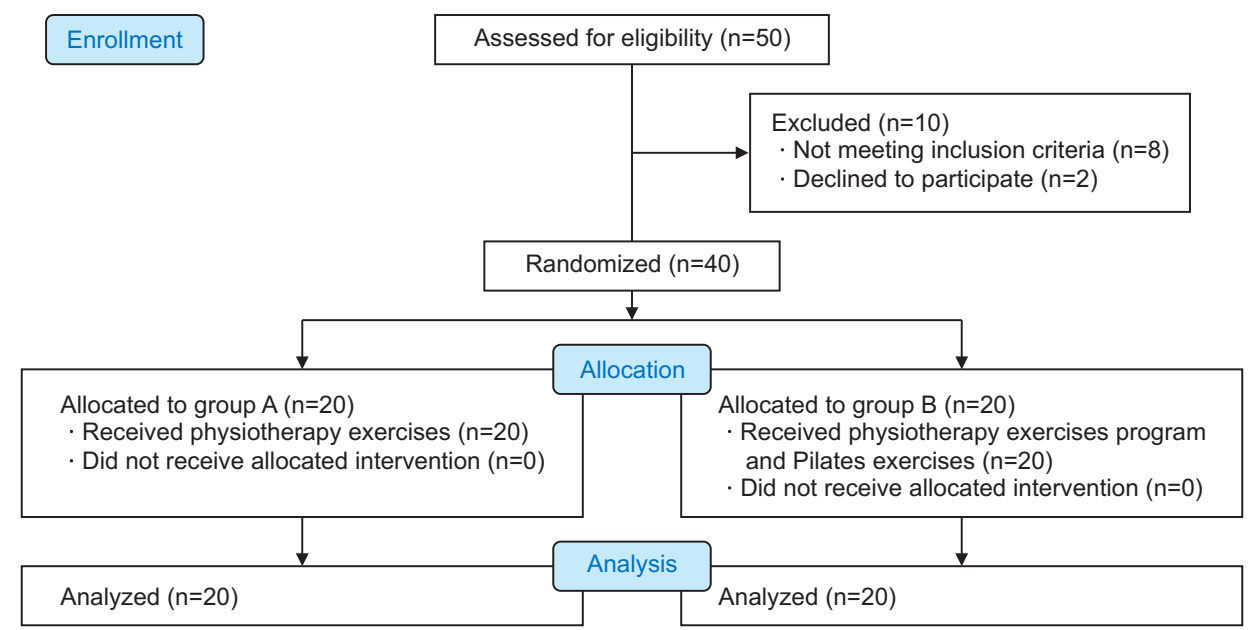

Fig. 1. Children's consort flow diagram.

Table 1. Basic characteristics of participants

\begin{tabular}{|lcrc|}
\hline & Group A & Group B & p-value \\
\hline Age (yr) & $8.40 \pm 0.68$ & $8.30 \pm 0.67$ & $0.65^{\mathrm{a})}$ \\
\hline Weight $(\mathrm{kg})$ & $24.87 \pm 2.94$ & $26.35 \pm 2.94$ & $\left.0.12^{\mathrm{a}}\right)$ \\
\hline Height $(\mathrm{cm})$ & $127.97 \pm 5.85$ & $130.42 \pm 4.60$ & $0.15^{\mathrm{a})}$ \\
\hline Gender & & & $0.74^{\mathrm{b})}$ \\
\hline Girl & $8(40)$ & $9(45)$ & \\
\hline Boy & $12(60)$ & $11(55)$ & \\
Modified Ashworth Scale & $11(55)$ & $7(35)$ & $0.20^{\mathrm{b})}$ \\
\hline Grade 1 & $9(45)$ & $13(65)$ & \\
\hline Grade 1+ & $6(30)$ & $8(40)$ & $0.44^{\mathrm{b})}$ \\
\hline GMFCS & $14(70)$ & $12(60)$ & \\
\hline Level I & 17 (medical shoes) & $4($ AFO) & \\
\hline Level II & 3 (AFO) & & \\
\hline Orthoses & & & \\
\hline
\end{tabular}

Values are presented as mean \pm standard deviation or number (\%).

GMFCS, Gross Motor Function Classification Scale; AFO, ankle-foot orthosis.

${ }^{\text {a) }}$-test, ${ }^{\text {b) }}$ chi-square test.

previous 6 months were all excluded. The clinical characteristics of the participants are described in Table 1. Before collecting data, we explained the aims, methods, and advantages of the study to the children's parents. Our research was performed in conformance with the Helsinki guidelines for human studies. All parents of the children signed a consent form before participation and approval was granted by ethical committee of Cairo University, Faculty of Physical Therapy approved the study (No. P.TREC/012/002914) and this study was registered at https://clinicaltrials.gov (Identifier: NCT04615793).

\section{Outcome measures}

\section{Pediatric Balance Scale (PBS)}

The PBS is a modified version of the Berg Balance Scale used to assess balance in children with mild to moderate motor disorders. The highest score is 56 points $[18,19]$. The scale assesses the performance of 14 common activities in daily living.

\section{Gross motor function}

Gross motor functional performance was assessed using the Gross Motor Function Measure (GMFM-88) [20]. 
It contains 88 items in five dimensions, ranging from lying and rolling to standing, walking, and running. Only the $\mathrm{D}$ (standing) and $\mathrm{E}$ (walking) dimensions were evaluated and the scores were presented as percentages.

\section{Intervention}

Group A performed flexibility, strength, and endurance exercises that focused on the lower extremity and trunk muscles, exercise for postural stability in various positions and surfaces, including flexibility exercises for the hip (flexors and adductors), knee (flexors and extensors), and calf muscle (15-second hold and five repetitions). Strengthening exercises included the core muscles (curlups, prone extension), hip abductors (side lying with a weight around the ankle), hip extensors (in prone position), hamstrings (prone knee flexion), and quadriceps (knee extension in high sitting). Postural control involved walking in all directions, exceeding the limits of stability in various positions such as kneeling, half kneeling, standing on rough and soft surfaces, stepping down and up, walking and standing in tandem, and standing on one limb (eyes closed and open). Each session started with a warming up and cooling down of 5 minutes for each period and each session lasted for 45 minutes.

Group B received the same program of exercises given to group $\mathrm{A}$ in addition to 45 minutes of Pilates exercises
(Table 2) to improve lower-limb strength, flexibility, and coordination. Exercises were performed on a mat, a medical ball, and from a standing position, focusing on maintaining core contraction, spinal and pelvic alignment, and respiration rhythm. Ten repetitions of Pilates exercises were performed with a 2-minute rest period between repetitions [21]. Both groups attended the intervention program three times/week for 10 weeks. All the children were cooperative during the treatment sessions, and the adherence rate was approximately $97 \%$.

\section{Sample size}

Based on a pilot study, we calculated the pre-study sample size using $\mathrm{G}^{*}$ Power statistical software (version 3.1.9.2; Heinrich-Heine-Universität Düsseldorf, Düsseldorf, Germany) $-\mathrm{F}$ tests (MANOVA: repetitive interaction measures), $\alpha=0.05, \beta=0.82$, and large effect size $=0.46-$ and showed that $\mathrm{n}=40$ was an acceptable sample size for this research [22].

\section{Data analysis}

We used the t-test to analyze the participants' characteristics and the chi-square test to compare sex distribution among the groups. The normal distribution of the data was tested using the Shapiro-Wilk test, and group homogeneity was determined using Levene's homogene-

Table 2. Pilates exercises

\begin{tabular}{|c|c|}
\hline & Description \\
\hline $\begin{array}{l}\text { Hundred } \\
\text { (head is positioned down) }\end{array}$ & $\begin{array}{l}\text { Practiced in a supine position on a mat. The two lower limbs are lifted together to about } \\
30^{\circ} \text { off the mat (first with flexion of the knee then with the extension of the knee). }\end{array}$ \\
\hline Shoulder bridge & $\begin{array}{l}\text { Practiced in a crook lying position on a mat by raising the pelvis off the mat; advanced to } \\
\text { using a medical ball under the lower leg while lifting the pelvis. }\end{array}$ \\
\hline Single-leg circles & $\begin{array}{l}\text { Practiced in a supine position on a mat by trying to make circles with each lower extrem- } \\
\text { ity, one at a time. }\end{array}$ \\
\hline Alternate toe touch & $\begin{array}{l}\text { Practiced on the mat by trying to touch the toes with both hips and knees in } 90^{\circ} \text { flexion } \\
\text { while alternating sides. }\end{array}$ \\
\hline Leg pull front & $\begin{array}{l}\text { A medical ball was placed under one lower leg while lying on a mat in a quadruped posi- } \\
\text { tion and was pulled forward and backward. }\end{array}$ \\
\hline Back twist & $\begin{array}{l}\text { Practiced while kneeling on the mat and abducting the upper extremity to } 90^{\circ} \text { while the } \\
\text { spine is twisted from one side to the other. }\end{array}$ \\
\hline Ball leg lifts & Practiced by sitting on a medical ball and alternately raising each leg off the ground. \\
\hline Standing splits & $\begin{array}{l}\text { Practiced by standing on one leg with the other leg on a medical ball and moving the ball } \\
\text { away from the stance leg and back. }\end{array}$ \\
\hline Ball wall squat & $\begin{array}{l}\text { Semi-squats performed while standing against a wall with a medical ball in the lumbar } \\
\text { area. }\end{array}$ \\
\hline Walking intandem & Walking in a straight line from heel to toe. \\
\hline
\end{tabular}


ity test. Within and between groups, the effects on PBS and GMFM-88 were analyzed by mixed MANOVA. We used the Bonferroni correction to perform multiple posthoc tests. The significance level was set at $\mathrm{p}<0.05$. All statistical tests were conducted using SPSS version 25 (IBM SPSS, Armonk, NY, USA).

\section{RESULTS}

\section{Subject characteristics}

There was no significant difference in subject characteristics between the two groups ( $p>0.05)$, as shown in Table 1.

Treatment effect on PBS and GMFM-88 (standing and walking)

The interaction between treatment and time was significant (Wilks' Lambda $=0.28, \mathrm{~F}=30.67, \mathrm{p}=0.001, \eta^{2}=0.72$ ). Time had a significant main effect (Wilks' Lambda $=0.02$, $\left.\mathrm{F}=583.84, \mathrm{p}=0.001, \eta^{2}=0.98\right)$. Treatment had a significant main effect (Wilks' Lambda $=0.63, \mathrm{~F}=7.11, \mathrm{p}=0.001$, $\left.\eta^{2}=0.37\right)$.

\section{Comparison within group}

Both groups' PBS, dimension (D), and dimension (E) results were significantly different after the intervention compared with the pre-treatment findings. The PBS, dimension (D), and dimension (E) scores in groups $A$ and $B$ increased significantly after therapy compared to the scores before therapy $(\mathrm{p}<0.001)$ (Table 3$)$.

\section{Comparison between groups}

There were no significant differences among the groups in any pre-treatment results ( $\mathrm{p}>0.05)$. After treatment, the PBS, dimension (D), and dimension (E) scores in group $B$ improved significantly $(p<0.001)$ when compared with the scores in group A (Table 3 ).

\section{DISCUSSION}

In this study, we investigated how Pilates exercises affect gross motor function and balance in children with diplegic CP. We hypothesized that Pilates exercises could help children improve their gross motor function and balance. Our findings showed that Pilates exercises combined with selected physical therapy programs enhance gross motor function and balance compared to selected physical therapy alone.

Some studies on Pilates's exercise showed that there is no reliable evidence regarding the duration of the program [23-25]. We conducted a 10-week program and found a significant improvement in the GMFM and balance scores. We concluded that the duration of the training program was adequate to improve gross motor functions and balance in these children.

At the end of the treatment period, both groups of children demonstrated significant improvements in standing and walking tasks, as well as balance, which may be due to increased muscle strength and endurance. A functional strengthening program can help children with mild spastic diplegia enhance their basic motor skills, functional muscle strength, and walking ability [26]. This is consistent with previous studies that showed that Pilates exercises improved lower limb muscle strength $[11,27]$.

Pilates exercises can improve flexibility, which is an important element of fitness that can help achieve opti-

Table 3. Statistical analysis of the Pediatric Berg Balance and dimension D (standing) and E (walking) of a Gross Motor Function Measures pre- and post-treatment

\begin{tabular}{|c|c|c|c|c|c|c|c|c|}
\hline & \multicolumn{3}{|c|}{ Pre-treatment } & \multicolumn{3}{|c|}{ Post-treatment } & \multicolumn{2}{|c|}{ p-value ${ }^{\text {b) }}$ (pre vs. post) } \\
\hline & Group A & Group B & p-value ${ }^{a)}$ & Group A & Group B & p-value ${ }^{a)}$ & Group A & Group B \\
\hline $\begin{array}{l}\text { Pediatric Berg } \\
\text { Balance test (score) }\end{array}$ & $35.55 \pm 1.35$ & $35.95 \pm 1.43$ & 0.37 & $38.70 \pm 1.21$ & $40.90 \pm 1.20$ & 0.001 & 0.001 & 0.001 \\
\hline \multicolumn{9}{|l|}{$\begin{array}{l}\text { Gross Motor } \\
\text { Function Measure (\%) }\end{array}$} \\
\hline Dimension E & $71.25 \pm 2.07$ & $71.40 \pm 1.87$ & 0.81 & $76.10 \pm 2.59$ & $80.25 \pm 2.02$ & 0.001 & 0.001 & 0.001 \\
\hline Dimension D & $64.25 \pm 1.68$ & $63.95 \pm 1.76$ & 0.58 & $71.75 \pm 1.29$ & $73.90 \pm 1.25$ & 50.001 & 0.001 & 0.001 \\
\hline
\end{tabular}

Values are presented as mean \pm standard deviation.

${ }^{\text {a) }}$ Comparison between the group, ${ }^{\text {b) }}$ comparison within the group. 
mum musculoskeletal function and enhance peak performance. In addition, it significantly enhances the functional flexibility of the adductors and hip flexor muscles [28].

Trunk control determines balance, gait, and functional activity during the early period. Therefore, the significant improvement in standing and walking tasks and balance could be attributed to improved postural control. This is in line with the findings of a study carried out in 2011 [29], which showed that postural correction plays a major role in movement efficiency by establishing a steady base during active limb movement. In addition, our study was similar to a previous one that showed that Pilates exercises can be used to enhance muscle strength and postural control while standing in children with CP [30].

Regarding the impact of Pilates exercises in conjunction with a selected physical therapy program, group B showed improvement in GMFM scores, in activities like standing on one leg, stepping up and down, and climbing stairs with alternating feet without support. This was consistent with the findings of a study which stated that maintaining stability while standing on one leg is necessary for several daily activities such as climbing up and downstairs and overcoming obstacles [31].

Group B showed significant improvement in scores of GMFM and balance, possibly because Pilates strengthens deep muscles such as the transverse abdominal and internal oblique muscles, which are responsible for core stability and may play a role in improving spine stability, muscle strength, and pelvic and hip joint flexibility $[32,33]$.

Group B showed a significant improvement in balance, suggesting that improving the subjects' balance is essential for sustaining and controlling stature and posture [34]. The improvement in functional balance observed in the Pilates group was compatible with the findings of a previous study which showed that subjects with low baseline balance ratings tend show significant improvements following Pilates exercise [35]. Previous trials assessed patients with multiple sclerosis, and proved that following Pilates exercise, patients with multiple sclerosis who used a wheelchair as well as ambulatory patients demonstrated significant improvement in stability and balance $[36,37]$.

One aspect that may have led to further progress in group B was the exercise method used. Exercises in- volve maintaining posture stability while focusing on the breathing rhythm, enabling a multi-tasking activity with enhanced proprioceptive awareness and kinesthetic movement coordination.

This study had several limitations. First, a lack of direct measurement of muscle power. The results are based on short-term outcomes, and there was no follow-up of the children to ensure the long-term maintenance of the improvement. Further study is needed to confirm the maintenance of the weekly exercise effect. Second, the difference in the exercise time (quantity) for each group. Further studies should be conducted to show the effect of Pilates exercises on different measured outcomes, as the improvement in this study could be attributed to the differences in the duration of exercise rather than the type of exercise.

Limited studies on the influence of Pilates exercises on different types of spastic CP highlight the need for future research in this area. There is a need to continue publishing case studies, case series, and randomized controlled trials to evaluate these interventions.

In conclusion, this study showed that both Pilates and conventional physical therapy training programs led to significant improvement in gross motor function and balance in children with CP. However, Pilates intervention in addition to conventional therapy was found to have greater benefits than the conventional physical therapy training program alone. Thus, Pilates can be combined with other physical exercises to improve standing, walking, and balance.

\section{CONFLICT OF INTEREST}

No potential conflict of interest relevant to this article was reported.

\section{ACKNOWLEDGMENTS}

The researchers are grateful for the cooperation of all the children and their parents and for their participation in this research.

\section{AUTHOR CONTRIBUTION}

Conceptualization: Abd-Elfattah HM, Galal DO, Aly MI, Aly SM, Elnegmy TE. Methodology: Abd-Elfattah HM, 
Elnegmy TE, Galal DO. Formal analysis: Aly SM, AbdElfattah HM. Original draft: Abd-Elfattah HM. Writing review and editing: Abd-Elfattah HM, Aly MI. Approval of the final manuscript: All authors.

\section{REFERENCES}

1. Richards CL, Malouin F. Cerebral palsy: definition, assessment and rehabilitation. Handb Clin Neurol 2013;111:183-95.

2. Guy JA, Micheli LJ. Strength training for children and adolescents. J Am Acad Orthop Surg 2001;9:29-36.

3. Emara HA, El-Gohary TM, Al-Johany AA. Effect of body-weight suspension training versus treadmill training on gross motor abilities of children with spastic diplegic cerebral palsy. Eur J Phys Rehabil Med 2016;52:356-63.

4. Brien $M$, Sveistrup H. An intensive virtual reality program improves functional balance and mobility of adolescents with cerebral palsy. Pediatr Phys Ther 2011;23:258-66.

5. Newell D, Shead V, Sloane L. Changes in gait and balance parameters in elderly subjects attending an 8-week supervised Pilates programme. J Bodyw Mov Ther 2012;16:549-54.

6. Mokhtari M, Nezakatalhossaini M, Esfarjani F. The effect of 12-week Pilates exercises on depression and balance associated with falling in the elderly. Procedia Soc Behav Sci 2013;70:1714-23.

7. Bernardo LM. Pilates for nurses. Pa Nurse 2005;60:27.

8. Keays KS, Harris SR, Lucyshyn JM, MacIntyre DL. Effects of Pilates exercises on shoulder range of motion, pain, mood, and upper-extremity function in women living with breast cancer: a pilot study. Phys Ther 2008;88:494-510.

9. Wells C, Kolt GS, Bialocerkowski A. Defining Pilates exercise: a systematic review. Complement Ther Med 2012;20:253-62.

10. Emery K, De Serres SJ, McMillan A, Cote JN. The effects of a Pilates training program on arm-trunk posture and movement. Clin Biomech (Bristol, Avon) 2010;25:124-30.

11. Bird ML, Hill KD, Fell JW. A randomized controlled study investigating static and dynamic balance in older adults after training with Pilates. Arch Phys Med Rehabil 2012;93:43-9.
12. Curnow D, Cobbin D, Wyndham J, Boris Choy ST. Altered motor control, posture and the Pilates method of exercise prescription. J Bodyw Mov Ther 2009;13:10411.

13. da Fonseca JL, Magini M, de Freitas TH. Laboratory gait analysis in patients with low back pain before and after a Pilates intervention. J Sport Rehabil 2009;18:269-82.

14. Sekendiz B, Cug M, Korkusuz F. Effects of Swiss-ball core strength training on strength, endurance, flexibility, and balance in sedentary women. J Strength Cond Res 2010;24:3032-40.

15. Hennington G, Johnson J, Penrose J, Barr K, McMulkin ML, Vander Linden DW. Effect of bench height on sit-to-stand in children without disabilities and children with cerebral palsy. Arch Phys Med Rehabil 2004;85:70-6.

16. Bohannon RW, Smith MB. Interrater reliability of a modified Ashworth scale of muscle spasticity. Phys Ther 1987;67:206-7.

17. Palisano R, Rosenbaum P, Walter S, Russell D, Wood E, Galuppi B. Development and reliability of a system to classify gross motor function in children with cerebral palsy. Dev Med Child Neurol 1997;39:214-23.

18. Chen CL, Shen IH, Chen CY, Wu CY, Liu WY, Chung CY. Validity, responsiveness, minimal detectable change, and minimal clinically important change of Pediatric Balance Scale in children with cerebral palsy. Res Dev Disabil 2013;34:916-22.

19. Franjoine MR, Darr N, Held SL, Kott K, Young BL. The performance of children developing typically on the pediatric balance scale. Pediatr Phys Ther 2010;22:350-9.

20. Safei I, Moeliono MA, Prabowo T. Loaded and unloaded sit-to-stand strengthening exercises effect to gross motor function measure in spastic diplegia cerebral palsy patients. Int J Integr Health Sci 2016;4:814.

21. Surbala L, Khuman PR, Trivedi P, Devanshi B, Mital V. Pilates versus conventional balance training on functional balance and quality of life in elderly individuals: a randomized controlled study. Sch J App Med Sci 2014;2(1B):221-6.

22. Eng J. Sample size estimation: how many individuals should be studied? Radiology 2003;227:309-13.

23. Brown TM. Power and sample size in clinical studies. 
J Nucl Cardiol 2015;22:1314-5.

24. Latey P. The Pilates method: history and philosophy. J Bodyw Mov Ther 2001;5:275-82.

25. Levine B, Kaplanek B, Scafura D, Jaffe WL. Rehabilitation after total hip and knee arthroplasty: a new regimen using Pilates training. Bull NYU Hosp Jt Dis 2007;65:120-5.

26. Liao HF, Liu YC, Liu WY, Lin YT. Effectiveness of loaded sit-to-stand resistance exercise for children with mild spastic diplegia: a randomized clinical trial. Arch Phys Med Rehabil 2007;88:25-31.

27. Rydeard R, Leger A, Smith D. Pilates-based therapeutic exercise: effect on subjects with nonspecific chronic low back pain and functional disability: a randomized controlled trial. J Orthop Sports Phys Ther 2006;36:472-84.

28. Kish R. The functional effects of Pilates training on dancers [dissertation]. Long Beach, CA: California State University; 1998.

29. Bahramizadeh M, Mousavi ME, Rassafiani M, Aminian G, Ebrahimi I, Karimlou M, et al. The effect of floor reaction ankle foot orthosis on postural control in children with spastic cerebral palsy. Prosthet Orthot Int 2012;36:71-6.

30. Dos Santos AN, Serikawa SS, Rocha NA. Pilates improves lower limbs strength and postural control during quite standing in a child with hemiparetic cerebral palsy: a case report study. Dev Neurorehabil 2016;19:226-30.
31. Kisner C, Colby LA. Therapeutic exercise: foundations and techniques. 6th ed. Philadelphia, PA: F. A. Davis Company; 2012.

32. Culligan PJ, Scherer J, Dyer K, Priestley JL, GuingonWhite G, Delvecchio D, et al. A randomized clinical trial comparing pelvic floor muscle training to a $\mathrm{Pi}$ lates exercise program for improving pelvic muscle strength. Int Urogynecol J 2010;21:401-8.

33. Phrompaet S, Paungmali A, Pirunsan U, Sitilertpisan P. Effects of Pilates training on lumbo-pelvic stability and flexibility. Asian J Sports Med 2011;2:16-22.

34. Mohammadi M, Kaldirimci M, Kazemi SE, Mizrak O, Tugrulhansam C. The effect of Pilates exercise on gait speed and strength of lower limb in elderly male. Adv Appl Sci Res 2015;6:1-6.

35. Irez GB, Ozdemir RA, Evin R, Irez SG, Korkusuz F. Integrating Pilates exercise into an exercise program for $65+$ year-old women to reduce falls. J Sports Sci Med 2011;10:105-11.

36. Guclu-Gunduz A, Citaker S, Irkec C, Nazliel B, BaturCaglayan HZ. The effects of Pilates on balance, mobility and strength in patients with multiple sclerosis. NeuroRehabilitation 2014;34:337-42.

37. van der Linden ML, Bulley C, Geneen LJ, Hooper JE, Cowan P, Mercer TH. Pilates for people with multiple sclerosis who use a wheelchair: feasibility, efficacy and participant experiences. Disabil Rehabil 2014;36:932-9. 